\title{
The stone of fools
}

\section{Giorgio Bordin}

Received: 19 February 2011/ Accepted: 19 April 2011/Published online: 6 July 2011

(C) Springer-Verlag 2011

We previously wrote ( $J$ Med Pers 2011;9:34-35) that madness refuses to be subjected to bare logical, mechanical or materialistic explanations. However, no time in our history has been spared from this temptation. In the middle ages, a popular thought was that madness ensued as a result of a stone in the brain (Fig. 1). The phrenopathic incision,

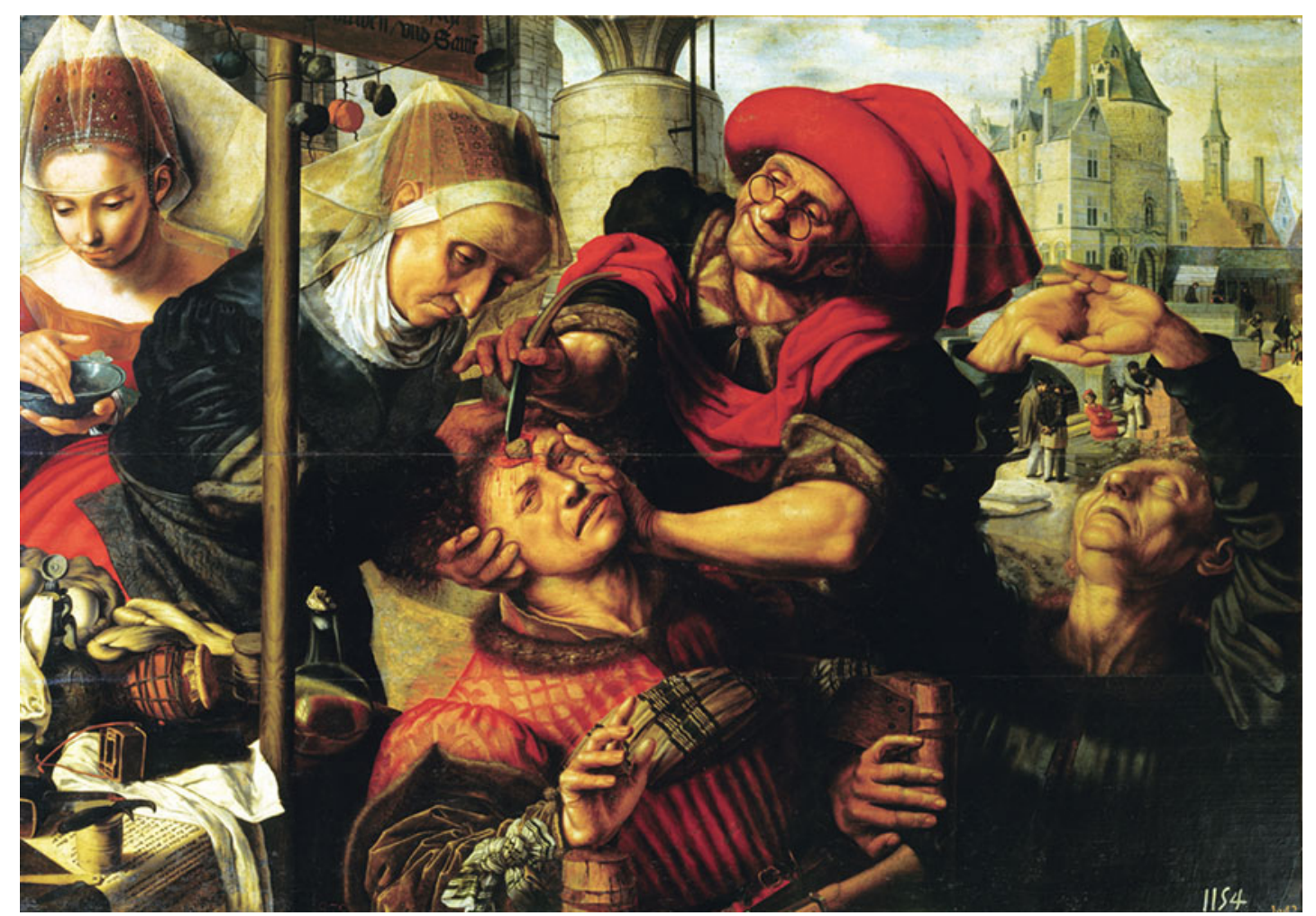

Fig. 1 Jan Sanders van Hemessen (c. 1500-c. 1556), The surgeon (Extracting the stone of madness), 1550. Oil on canvas. Madrid, Museum of Prado, with permission, (c) Foto Scala Firenze 2011

G. Bordin ( $\square)$

Hospital Piccole Figlie, Parma, Italy e-mail: giorgio.bordin@fastwebnet.it 
here depicted by the brush of van Hemessen, was made by quacks, who were used to going around villages to tend to those who were willing to undergo treatment. The scene is placed in a citizen landscape, where the common daily life flows, uninterested in the drama of the man in the foreground: drops of blood and tears fall equally from his body and his soul. The compassionate gesture of the man on the right balances the little table on the left, with the tools for surgery and a document, probably a fake certificate of qualification for surgery.

Actually, not everyone fell for such a simplistic treatment for madness, but many reasons concurred for the spread of this belief. Among them was the acceptance of many patients for whom, to be judged as fools and, to be healed by a surgeon could avoid involvement in witchcraft or more serious charges of demoniac possession.

Today, we consider these notions as both grotesque and superficial. But in the ultimate analysis, the evergreen claim for an organic nature of psychiatric illnesses is by far the better antidote for fears and shame of the patients, and the better self-esteem agent for physicians, who can easily find a clue to the pathogenesis without continuously being compelled by human nature to remember that the mystery of a madman cannot be reduced to a gear jammed by a rock. 